\title{
From the Western classics to the world: secondary music teachers' changing attitudes in England, 1982 and 1998
}

\section{Lucy Green}

\begin{abstract}
Two parallel samples of secondary music teachers in England, taken from 1982 and 1998, reveal similarities and differences in their evaluations and uses of twentieth and pre-twentieth century Western classical music, folk music, popular music, jazz and 'world' music. Least change occurs with relation to folk and pre-twentieth century classical music; most with relation to popular and world musics. The status of classical music is high in each of the two time periods, but in different ways. By the end of the century, teachers' views of musical value have overall, shifted radically towards more global perspectives, and their classroom approaches include far more integrated practical work involving performing, composing and listening, with an emphasis on cross-stylistic comparisons and musical universals.
\end{abstract}

\section{Introduction}

In the increasingly packed music timetable of many countries, the traditional curriculum content of Western classical and folk music now jostles with that of classical, folk, traditional, popular and jazz styles from all over the world. Although the research and professional literature on music education strongly reflect these major curriculum changes, there has been relatively little investigation of the changing attitudes and values of teachers themselves, concerning the different musics now included in their day-to-day work. This article will compare and contrast some of the attitudes and values expressed by two samples of music teachers in England, at the beginning and end of the final two decades of the twentieth century.

In 1982 I conducted a questionnaire-survey of sixty-one music teachers, each in a different school in different parts of England (Green 1988). The schools were all state secondaries, mostly mixed comprehensives, located in a range of rural and urban areas, the latter including London, Manchester and Birmingham. The survey included four questions: 'Do you teach (1) folk; (2) classical; (3) popular; (4) creative and/or avant-garde music?' Teachers were asked to reply 'Yes' or 'No' to each question, and to give reasons for their answers. Sixteen years later, in 1998, I sent 
out another questionnaire including almost identical questions, and collected responses from exactly the same number of teachers. The schools were again state secondaries and from the same areas of England as those in the first sample, although I did not go in for precise pair-bypair matching. The questions in the more recent survey were altered to take account of two factors: firstly, changing conventions in the use of terminology between the early eighties and late nineties; and secondly, new legal requirements which had been introduced by the National Curriculum for England in the interim period. These made it mandatory for teachers to include 'music in a variety of styles, from the European "classical" tradition..., from folk and popular music, from the countries and regions of the British Isles, from cultures across the world, by well known composers and performers, past and present' (DFE 1995, p. 6). To cater for these changes, the term 'avant-garde' was replaced by 'twentieth century classical music'; questions about world music and jazz were added to the initial four questions of the 1982 survey; and the wording of the questions was altered. Instead of the direct 'Do you teach x music?', which might have been seen as compromising in the face of legal requirements, I asked 'To what extent do you teach x music?'. As well as prose responses, teachers were requested to rate each of the six styles in order of importance, from 'most important' to 'not at all important'.

Over a relatively short period of sixteen years, teachers' inclusion and relative estimation of diverse musical styles appear to have changed considerably. In the quantitative results from the 1982 survey, shown in Chart A (below), classical music took pride of place, being taught by all but three of the 61 teachers. Popular music was nonetheless included by a significant number, 46, which amounts to approximately 75 per cent of the sample. Folk music followed, with avantgarde/creative music bringing up the rear. By 1998, as Chart B (below) indicates, the prime position of classical music had given way. Greatest emphasis was now placed upon popular music, closely followed by classical music. Surprisingly, world music, which had not played an obvious role in the curriculum only sixteen years before, took virtually equal second place with classical music. Then came jazz and twentieth-century classical music, with folk music trailing behind.

Alongside this quantitative information, the prose responses in which teachers explained their reasons for including different musics, and described their approaches in class, afford rich insights into some of the underlying musical and educational values involved. In the remainder of this article I will examine these prose responses, concentrating mainly on areas that bear comparison of both similarities and differences, between the two time periods in question. After 
a brief look at folk and avant-garde/twentieth-century classical music, the bulk of the discussion will be devoted to classical and popular music, as these were the two areas which evidenced the greatest amount of change. At the end of the article I will consider the responses from 1998, concerning two styles that were not included in the 1982 survey - jazz and world musics. ${ }^{1}$

\section{CHART A: 1982}

60

$\mathrm{N}$

U $\quad 55$

$\mathrm{M}$

B $\quad 50$

E

$\mathrm{R} \quad 45$

O 40

$\mathrm{F}$

35

$\mathrm{T}$

A

C 25

$\mathrm{H}$

E 20

$\mathrm{R}$

S $\quad 15$

10

05

Classical Popular Folk Avant-garde

The chart shows the numbers of teachers out of 61 as follows:

$=$ who included the style in the curriculum

= who omitted the style for stated reasons of dislike and/or unfamiliarity

NB: The overall figures for each style add up to much more than the total number of teachers, because most teachers included more than one style. Twenty-one teachers included all four styles. 


\section{CHART B: 1998}

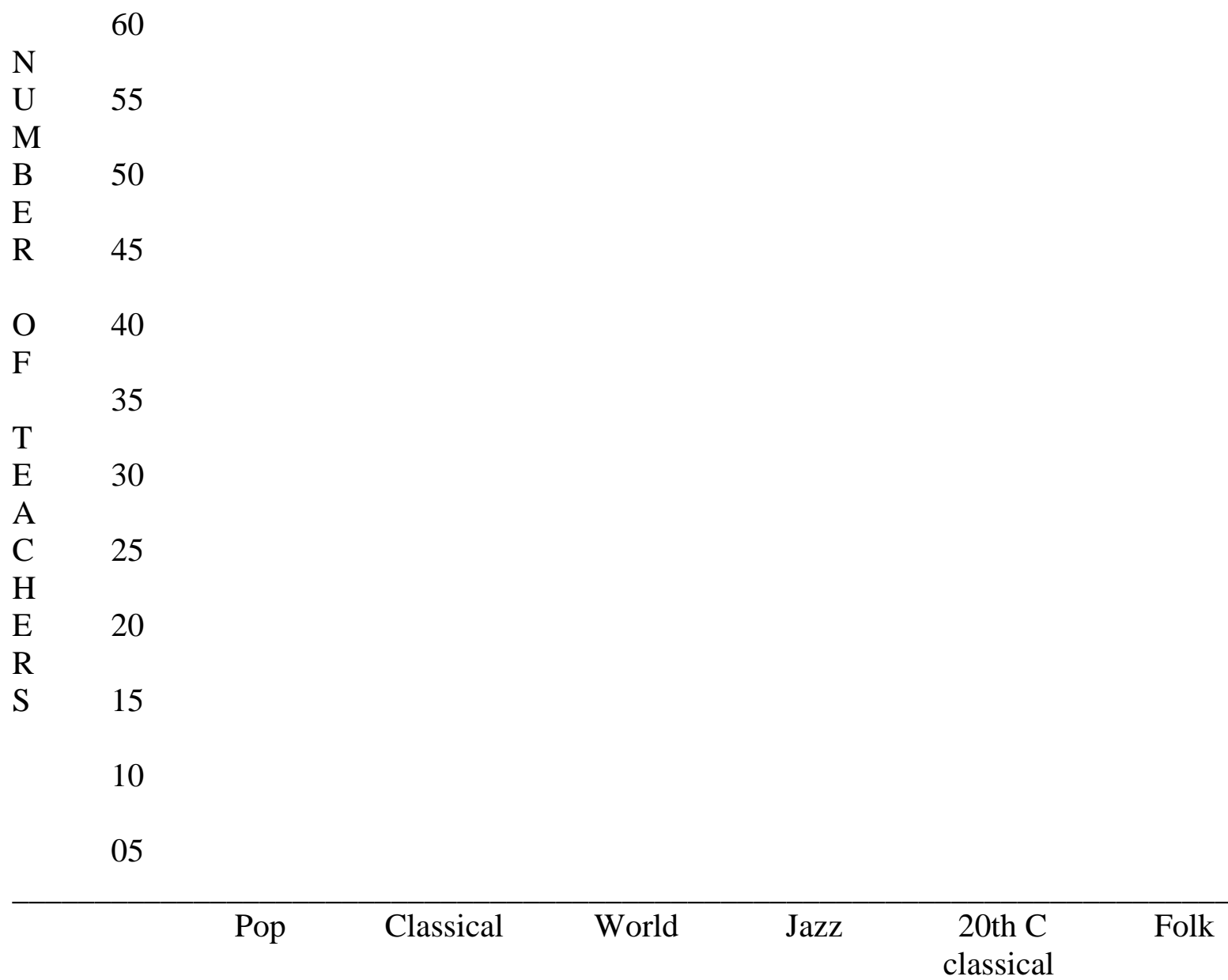

The chart shows the number of teachers who rated each style as follows:

$=3$ (most important) or 2 (moderate importance)

$=1$ (least important) or $\mathrm{N}$ (not taught at all) 


\section{Folk music}

Folk music was treated with lukewarm enthusiasm in both questionnaires. For example:

1982

-What does 'teach "folk" music' mean? Of course we sing folk songs - is that it?

The pupils know what I mean when I say 'folk music'. It has value for cultural roots.

-I personally am not a 'folk' enthusiast and I can only teach well the things that I personally am enthusiastic about.

1998

-Not much. Neither they nor I listen to it much - I think. But it does crop up from time to time.

-Not very much - this is perhaps an area that we neglect.

However the meaning of the term 'folk music' appeared to be different in many teachers' minds between the two questionnaires. In 1982 it was taken for granted that the term referred to music of the British Isles or at the furthest extreme, Europe. By 1998, in spite of the fact that the National Curriculum documentation made it quite clear that folk music should be taught, and in spite of the fact that the exact wording of my question was: 'To what extent do you include folk music of the British Isles?', a number of teachers responded more in terms of folk music of the world in general. Here are 6 out of 12 possible examples:

1998

-Folk Music in India - Year 9. Folk Music of British Isles - None. Reason - time.

-Shamefully very little. World music generally means we look at Indian, African and Indonesian styles.

-A small amount of listening in Yr 9. In more depth for the world music section of the GCSE exam.

-Not done - 1 hour per week therefore time limited. No resources at present...if I were to do this it would be a tiny part of a whole package of 'World Music' etc.

-Approximately 5\% of time. Syllabus mainly exam-orientated at KS4. Emphasis on 'worldwide music' is slowly replacing folk music.

-I use some folk music...but don't teach specific regional music. The school is multicultural so more time and energy is spent using the huge pool of cultural resources from around the world. Time limits study of folk music of all pupils in school, and I have no wish to suggest that one culture is superior to another. 


\section{Avant-garde/twentieth-century classical music}

In 1982 half the teachers (32) were very enthusiastic or at least positive about the use of 'avantgarde and/or creative music'. The reasons they gave were mainly that this music was associated with contemporary developments in music education, especially work by Paynter and Aston 1970, (also see e.g. Self 1967, Dennis 1970, Schafer 1967) which, they said, helped to stimulate pupils' imaginations. These developments involved pupils in practical music-making, including composition and improvisation, often in a free and/or atonal idiom.

However at the same time as these positive responses, there was also a significant level of negativity towards the teaching strategies associated with creativity in the classroom. For example:

1982

-Try! Well it rather depends on the kids' state of mind! Making music with different musical instruments can be absolutely chaotic unless extremely well organised - no selfcontrol etc! Easier to organise graphic scores, rhythm exercises, using poems.

-Creative - very little. I have tried (God knows!) but the practical difficulties are tremendous.

-No...Without nerves of steel and an iron discipline (I have neither) the only kind of creativity possible here would be unpopular with surrounding classes. That is: my pupils if allowed to 'create', will hit, thump and blow as loudly as possible, and I have not yet found the strength to take them through that stage to the more creative aspect. 'Creativity' can also seriously diminish your stock of instruments if you haven't got eyes in the back of your head!

In addition, several teachers were negative about the notion of avant-garde music, (or what would now more commonly be termed modernist music), itself:

-Avant-garde - I cannot understand or appreciate it myself (on account of age?) so how can I 'teach' it or enable others to appreciate it?

-Avant-garde: Very little. I don't understand it from educational point of view. Very unsatisfying.

- No. This is because of the rather rough area in which I teach and also because I do not believe in 'avant-garde' music myself - I regard it as rubbish!

Altogether 17 out of the total 61 teachers made negative comments of this kind, sometimes encompassing both the creative and the avant-garde paradigms, sometimes one or the other, 
usually relating to problems of noise, lack of sound-proofing, amount of energy and organisation required on the part of the teacher, lack of resources, lack of confidence in the teaching techniques, and/or dislike of or incomprehension about avant-garde music in general.

In 1998 the positive reasons for teaching twentieth-century classical music were very similar to those expressed by teachers in 1982, as described above. But the level of negativity had significantly reduced, both in the numbers of teachers expressing it, and in its vehemence. Only two teachers said that they did not teach any music of this kind, but their comments were restricted to 'KS3', the 11 to 14 age-range only, and contained no derision or negativity towards the music itself:

1998

-At KS3 - None. I consider it too difficult for students in years 7-9 to appreciate: too easy to give the impression 20C music is just 'plinks \& plonks'...

-None. I do not feel this is appropriate, easy or necessary for children in KS3 to understand.

Amongst others who declared they taught only a small amount of such music, there were again no signs of antipathy. For example:

-We touch on some aspects of 20C classical music. However pupils find this a difficult area and are easily put off the music if it is not introduced in the right way.

-At KS3 we don't have modules, just teach it as it crops up e.g. Stravinsky, B. Britten. Don't know why really - needs exploring. Lots at KS4 - Serialism, Minimalism, Impressionism. Freedom of creativity excellent for illustrations e.g .Messiaen quartet 'End of Time'.

-Very little. Sometimes for listening questions. No specific reason for lack of teaching it perhaps the teaching aids I use don't promote it.

Finally, the exasperation or fear of losing control during creative practical sessions, which marked the comments of many teachers in 1982, were altogether missing in 1998. Furthermore, as will be seen from many angles in the course of this article, creative practical classroom work by now had no associations with any particular style of music over and above any other.

Two new aspects concerning the place of twentieth-century classical music in the classroom appeared in the 1998 responses. One concerned community links, an area of music education that had developed significantly during the 1990s in the UK, often involving composers working with 
pupils in schools (see e.g. Kushner 1991). Teachers from three schools mentioned this, of which one example is:

1998

-I place great emphasis on 20thC music. We, as a music department, are regularly involved in projects with contemporary ensembles and musicians producing compositions which students have performed at prestigious events, e.g. ISCM world music days with Steve Reich and Mauricio Kagel. Also work with Hallé composers in residence; Camden Reeves and Manchester ensembles eg Psappha. Also London Sinfonietta.

The other new area concerned the forging of connections between twentieth-century classical music and other musics. This mainly involved pre-twentieth century classical music, but there was also one reference to fusion and one to music for the Gamelan. Whereas 14 teachers declared that they connected all musical styles together, six made explicit and substantial connections with particular reference to the twentieth-century classical area. For example:

1998

-Year 7 - 'Peter Grimes', 'Rite of Spring'... Other areas use both 17-19C and 20C music as stimulus...Year 9 - Minimalism project (related to Gamelan, etc.).

-Similarly I use snippets of 20th Century music e.g. if I am looking at Opera my choice would include an example from 'Dido', 'Magic Flute', 'La Traviata', 'Madam Butterfly', 'Wozzeck'. In turn we are drawing comparisons and differences.

-Pupils are excited by living composers and find current/recent ideas accessible. Musique concrete; minimalism; serialism and various forms of fusion are all used as basis for composition and others used as examples when appropriate.

As will be seen in more detail later in the article, the emphasis on cross-stylistic similarities played a major part in many areas of the curriculum of the late 1990s.

\section{Classical music}

For two teachers in 1982, it seemed rather absurd to ask whether and why they taught classical music:

1982

-We listen to and perform classical music - particularly the Baroque. Do we need to give reasons - surely obvious! 
-Of course! The reasons should be obvious...

For three others, classical music was....

-...part of our heritage...

-The heritage should be presented before young pupils since the opportunity would not otherwise exist.

-Transmission of culture and all that...

Many implied in various ways that classical music was 'good music', or the 'best music', a position which was made explicit by six:

-It contains valuable musical elements....

-It offers the widest field of musical discovery - affords the greatest satisfaction to sing, play and listen to.

-....classical music has more to offer in terms of study...

-...basic grounding; techniques; standard background to any other musical developments. -Yes in so far as 'classical' = expressive, and in so far as it is an art form, and is the style of music that a) requires the greatest concentration and b) requires the greatest explanation and c) requires the greatest sensitivity.

-Yes...it is the background to most modern forms in music...It builds the 'foundations' securely.

Classical music was seen as a valuable preparation for adulthood, a means to fulfil the expectations of society and create a sense of responsibility in pupils. Out of 8 such comments:

1982

-It has value for what society expects.

-Encouragement of tomorrow's audience. Set standards ...

-A knowledge of music from the past is part of an educated person's cultural set-up.

-We find it creates a strict code of responsibility in pupils - form is so important.

By a similar token, classical music was considered to broaden children's knowledge and taste, often as part of a wide curriculum including diverse musical styles. Out of 16 such comments:

-Yes. As an aid to cultural development.

-Yes. Enrichment of experience.

-...I try to encourage broad tastes in children. I want them to appreciate to some degree all kinds of music. For this reason I do play some classical music as part of projects ... 
-I do spend some time in years 1-3 on appreciation of popular classics - it's general knowledge and beneficial to an all-round education...

-We teach children to listen and appreciate all kinds of music, so classical music is used as well as 'pop'. Our aims are to cultivate a 'listening' ear and to [illegible] knowledge culturally.

Classical music also had an extrinsic value in so far as it enabled a movement away from what was seen as pupils' staple diet of popular music. Out of 12 possible comments:

1982

-Yes [I teach classical music]. Since children have very little knowledge of any music apart from disco/pop etc. and therefore teaching classical music broadens their musical knowledge...

-Yes. Children have 'pop' thrust upon them every day and therefore we try to broaden their musical appreciation, but in an interesting way.

-Yes. It is something that not many children experience before they come to school and anything new is educational.

-Classical music is taught because I wish to bring children into contact with music which they never normally hear...

-Yes. Much of the fundamental aim for the work is to open windows and show an otherwise unknown world.

-Yes. I introduce children to classical music. Pop music they listen to anyway, there seems little point in teaching it therefore.

- ...I think it important that children should hear music other than the pop diet that they have fed off since they were infants...

A different approach to classical music was to disguise it:

1982

-Yes, but in such a way that it is non-stuffy. Restricted to relatively few pieces. Pupils are trained to listen.

-... I do play some classical music as part of projects but I camouflage it to avoid prejudice. E.g. if you play 'classical' music as a signature tune that kids know, they are more likely to listen. ... 
-I do spend some time in years 1-3 on appreciation of popular classics - it's general knowledge and beneficial to an all-round education. They also play and sing some 'classical' music while not necessarily realising that it's 'classical'.

-Yes. It exists in everyday life as background music to TV programmes and films, in advertisements, etc and is enjoyed in that context. Therefore it should be possible to remove the label 'classical' as a stigma.

In 1998, teachers were generally just as positive about classical music as they had been in 1982 . As in the earlier questionnaire, its status as part of 'our heritage' was mentioned by two teachers: 1998

-A lot, because I regard it as the most important part of our musical heritage, but I do not make a distinction between the 20th $\mathrm{C}$ and any other time as regards importance.

-Quite a lot - see above but also to do with it being our heritage.

One teacher also observed that classical music is:

-...the basis of our entire western musical culture.

Again, as in 1982, classical music was taught in order to broaden knowledge:

-Important to explode the myth that classical music is in some way 'inaccessible'.

-...[Classical music] gives all pupils a broader understanding of types of music and a historical perspective.

-All aspects of the curriculum and musical historical periods are important, they must be covered to make sense of the chronological structure.

-[Classical music] ... broadens musical knowledge.

...Although I would argue against the notion of progression it is still very useful to instil a knowledge of the development of Western Classical Traditions. ...

-Quite a lot - important to know the history of classical music in relation to general history, composing techniques etc.

But in other respects there was quite a different tone and emphasis in the teachers' answers. Unlike in 1982, no-one expressed any surprise at being asked to give reasons for the amount of emphasis they placed on classical music, and no-one openly claimed that classical music was a superior musical style. One new aspect was very evident in many responses, and has already been mentioned in connection with twentieth-century classical music above: that classical music was 
linked with popular music, jazz or world music. It is worth reproducing all the responses in this area:

1998

-I regularly refer to old music. The music I refer to I choose in relation to pop, and also because I love it. I am a kind of salesman of my (broad) musical tastes.

-I cover all the styles in the course of every year and make every effort not only to demonstrate the special qualities of each but also to draw out connections, especially with current examples in popular music. E.g. Guantanamera has recently been produced by FUGEES fused with rap.

-Large amount - linked with popular music...

-In KS3 I do a major project on Mozart, and am looking to expand the amount of 'classical' music in Yr 7 and Yr 9. I use pop techniques as a way into 'classical' music. -KS3: A lot of 'classical music' is listened to but is not studied per se: music may often be incidental to the nature of the project in progress i.e.: a project on 'instruments of the orchestra' will include music by Beethoven et al as well as Wynton Marsalis and contemporary music...

-Year 7: Warlock 'Suite' - Performance of Mattachins. Brittens YPGO - listening and composing variations. Vivaldi 'Four Seasons' - graphic notation. Year 8: Pachalbel Canon - 4 parts over chords. Use of melodies -various/changes every year. Year 9 Indian Classical music.

By a similar token, a number of teachers declared that they used classical music, along with a variety of other musics, in order to teach what they often referred to as musical 'elements' (a concept used in the National Curriculum documentation), 'devices', or 'universals' that cut across styles. Again, here are all the relevant responses:

1998

-Fairly strong emphasis [on classical music], usually within projects centred on learning specific forms or structures...As with all these classifications, the level of their inclusion in the curriculum is governed by the way in which projects are devised to further understanding of music and to give as broad and varied a set of experiences as possible. -All these areas come through different projects that we do, e.g. we don't teach classical music separately but as part of projects on ostinato/music with a story/instruments.

- ... [Classical music] helps with teaching of musical devices... 
-Elements of 'Classical' taught through differing genres...

-Some (5\%). Good for harmonic changes. Figures/texture/form.

-Some - features in Years 7-8 within projects relating to Elements of Music.

-Some, in all years...Texture, colour/timbre...

$-40 \%$ - used to relate to projects - not taught 'historically'.

-Used in many topics - particularly music they have heard e.g. certain classical music suitable for certain topics.

-Large amount - linked with popular music. Backs points raised in topics. Broadens musical knowledge.

-Again, we use examples of this in various schemes of work rather than focussing on it as a particular area of teaching.

The above contrast starkly with the 1982 responses, in which only one teacher had made such a connection:

1982

-I use 'classical' material for the same reasons as in question 12 above [on folk music], i.e. if it can tie in with the child's experience. E.g. Chapter 4 of 'Pop Music in School' [by Michael Burnett] - Blues Project, end of section 1: examples of riffs /ostinati in classical music.

\section{Popular music}

As already mentioned, about three-quarters of the teachers in 1982 stated that they included popular music in the curriculum. However, despite including it, there was nonetheless a significant amount of negativity and doubt surrounding it. Several teachers suggested that pupils already understood popular music, or already had access to it, the implication being that they therefore did not need to study it as part of their formal education:

1982

- No. We don't need to, except in the third year, when we introduce a lot of lighter and jazzy material...They don't need our help with what they already understand.

-If the situation arises, but not deliberately. There is little point. The young know far more about it than we do...

-...If anything, I get pupils to me teach about pop.

-No. The pupils seem sufficiently saturated in this cultural area to warrant its exclusion from the curriculum. 
-Use of some pop songs e.g. 'Brown Girl in the Ring', 'Superman'. If using records the lesson is poor - kids can hear these at home etc.

-Pop is covered and electric guitars etc. are available but I don't organise the group and take their rehearsals. They do that themselves...

-No. Most teenagers surround themselves with pop music 24 hours a day. Music lessons give the opportunity to show other music exists.

-...At end of each term I invent a crossword on [the] syllabus which they complete to a background of their records. Pop music is significant in so far as they can readily understand it but I point out that most of it is designed as a wallpaper of sound (perhaps to stop deep thought!).

Four teachers suggested that including popular music represented an intrusion into the pupils' world:

-If the situation arises, but not deliberately. There is little point...They will not take kindly to crossing the cultural barrier.

-No... They don't appreciate our prying into their world.

-...I also do a little in 3rd year about its roots but find that pupils prefer for really up-todate records to remain theirs. It has value for pupils.

-No. I've found in the past that classes are more 'hostile' to the 'wrong' kind of pop - and very partisan - rather than being indifferent /objective to 'classical'.

Some teachers questioned whether it was possible to 'teach' popular music at all:

1982

-Yes. The 3rd Year do a 'Pop' Project for the period of one half term (about 6 weeks) straight after 3rd Year exams to give them the opportunity to express their own knowledge and interests in music and exchange ideas with other pupils and learn to be critical. I don't mean so much 'teach' it but let them learn from others in group/magazines/books etc. as a break from classical music theory, history etc.

-Is it possible to 'teach' pop music?...

-What do you mean? We study the history of pop from 1900. Practically we work on chord structures etc. from 12 bar blues to modern musical trends.

-Yes...However I feel often as though I am preaching to the converted. They do not listen to a 'pop' tune in the way they might listen to, say, a piece by Stockhausen. They cannot 
be taught to listen to pop in a new way as easily as they can be taught to listen to something with which they have had no previous contact.

-'Teach' is an exaggeration as we do not have expertise. But we include the history of pop in our courses in years 1-3, and include class debate and discussion.

Two mentioned that the short-lived nature of popular music made it difficult to resource. For example:

-No. We don't need to, except in the third year, when we introduce a lot of lighter and jazzy material. The sort of thing they would find interesting is too fashionable and therefore too short lived to merit spending the large sums of money needed to supply a class of pupils...

By 1998, all the teachers in the sample declared that they included popular music. Only five of them were negative or expressed reservations, and even these comments were not marked by the vehemence found in many of the 1982 responses. For example:

1998

-Some - to maintain an interest in that which is contemporary, however peripheral.

-Not a great deal. I'm out of touch!

Amongst the vast majority of the teachers, the attitudes were substantially different to those expressed in 1982, displaying a relatively high level of respect for popular music and a welcoming attitude to its presence in the curriculum. For example, now only one teacher suggested that pupils have no need to study popular music in the classroom, and that classical music is pedagogically better:

-Not a lot. Pupils can be involved with this outside the classroom. Compositional techniques are easier taught through the classical medium.

No-one suggested that it is not possible to teach popular music, and only one teacher mentioned the problems of intrusion (avoiding "trying to be "trendy"), but he was nonetheless very enthusiastic about including popular music:

-Large scale assessed module in Yr 8 and many examples used anecdotally. Works excellently with Yr 8s - enthusiastic in their approach to singing contemporary tunes e.g. R. Kelly and Beatles, and this leads to extremely useful group composition work... Risky subject for teacher. I avoid trying to be 'trendy'. 
In his case-study of music teaching in the 1970s, Vulliamy (1977) observed that although popular music was included in the curriculum, teachers tended to use it with low ability pupils, often in order to motivate them, thus implicitly making it appear to be inferior, whilst reserving the higher-status classical music for the more able pupils. Similar sentiments were expressed by the 1982 survey teachers cited below:

1982

-Yes, in 3rd Year. To find a point of contact with less musically motivated pupils...

-I teach a superficial survey of the history of pop to middle and low band [i.e.ability] 3rd years in the final term of the 3rd year. It keeps their interest alive when they are (most) not continuing with the subject next year...

-Sometimes - an attempt to interest pupils otherwise apathetic.

-Yes - a three-term course in 3rd year. Starting with jazz, big band, 50s, 60s and recent trends. Since the inauguration of this course, I have found that 'aggression' I often found with 3rd year groups has disappeared.

-3rd year studying the 'History of Pop Music' as part of written work - listen to records etc. to realise different styles. They seem to find this more interesting than 'History of Classical Composers' etc.

Swanwick (1968), Vulliamy (1977) and Green (1988) amongst others, also noted that popular music was often used as a 'treat' at the end of the lesson, after exams, or at the end of the course as a whole. This relegation communicated a message that it was of less importance than the exam-orientated classical music which formed the main body of the course. In common with many of the comments from 1982 above, this meant that popular music was not included until the 3rd year (age 13-14), by which time the vast majority of pupils had already opted out of music for their future 'O' level or CSE careers. By contrast, in 1998 no-one said they used popular music with low-ability children, although one teacher mentioned its use with younger children:

$-\ldots$ The lower years find it easier to relate to.

Amongst those teachers in 1982 who were more enthusiastic about popular music's place in the curriculum, ten mentioned its interest for and relevance to pupils as a good reason for including it, and one mentioned that pupils enjoy it. For example:

1982 
-Yes...It serves the musical needs of most young people. Young people can relate to it easily...

-Yes. Relates to age group...

-It is the main interest of Young People today.

-Yes. One has to cater for the tastes of today's children, which means including 'pop' music in the curriculum...

-Often use 'pop' material. Because it is the musical idiom usually closest to the children's own experience...

-Yes. Children enjoy it and relate to it very quickly. However I feel often as though I am preaching to the converted...

In 1998, 28 teachers, which is nearly three times as many as in 1982, said they included popular music on the grounds that pupils enjoy it, can relate to it, and find it relevant. Here are 14 out of the 28 examples:

1998

-A lot - because it appeals to most pupils and from that interest you can develop into other areas.

-Pupils...respond well to it - it is a type/style of music that they can understand and it is relevant to them...

-Very important to curriculum - we use it a lot ...pupils and teachers enjoy it ...

-... Students access this type of music easily so I do favour listening examples in this style

$\cdots$

- ... From Year 9 onwards students have every opportunity to compose in popular styles if they wish, as for many of them it is their main musical diet and a way of keeping them involved in music making.

- I think this is an important topic as students relate to 'popular music' and this is reflected in their compositions, performances and the music they listen to.

-...pupils enjoy using [pop]for singing and performances.

-...relates to students' own experiences.

-... it is useful for us to work from a shared/common experience rather than working from works/composers completely outside the pupils' normal experience.

-Popular Music accessible to students. They enjoy playing it...

-...Works excellently with Yr 8's - enthusiastic in their approach to singing contemporary tunes... 
-...Links are constantly drawn between pupils' personal listening habits and music dealt with as part of KS3/4.

-...I feel it is more effective to teach them through a medium they know and can relate to and are interested in. I like to view music as fun and I feel this is the best way to do that. -...pop music relates to our pupils...pupils enjoy performing pop music.

In 1982 one reason for including popular music, was to enable pupils to develop discriminatory powers or critical attitudes towards it. Out of 10 examples:

1982

-Yes...We teach them to listen critically to it...

-...They can study its historical development, styles, social background etc. and begin to look at it objectively and critically.

-I teach a superficial survey of the history of pop to middle and low band 3rd years... It teaches (hopefully) some discrimination in listening...

-Yes...Understanding of history and development hopefully leads to more discriminating listening and an understanding of 'good' music and 'second rate' music...

-Yes...To help give an understanding and discriminating appreciation of 'pop' culture...

-The development of 'pop' music is taught...It is also desirable that pupils become discerning in their approach to popular music, rather than being in total acceptance of whatever the media has to say.

By 1998, only one teacher mentioned that popular music was included so as to aid pupils' discrimination; and this was in a very positive overall context:

1998

-About half of our curriculum time is spent on teaching 'popular music'...They respond well to it - it is a type/style of music that they can understand and it is relevant to them. They can also develop an understanding of the music that they listen to out of school. Pupils prefer to compose in a popular style as they tend to understand it - they also have a clear idea as to what they hope to achieve...

In 1982, five teachers made explicit statements that popular music was a valuable style, or had equal value to other styles:

1982

-Yes...It contains valuable musical elements. 
-Yes...No type of music is more valid or important than another.

-Yes - because it is music. It is our job to educate and stimulate not just indoctrinate and bulldoze children into liking one particular style of music. Music should be food for thought and a well-balanced and varied diet should be included - from bangers and mash to duck à l'orange!

-I often use 'pop' material...'Pop' can be musically stimulating and worthy of attention. -YES! Why not? It is music. The College is releasing a 'Pop Record' to celebrate the birth of the baby of Princess of Wales.

However, apart from the first one, these comments contain an implicit defensiveness. Why state that 'no type of music is more valid or important than another', unless to rebut a potential objection to a particular style? No teacher made such a statement about classical music. Similarly, no-one found it necessary to point out that classical music was 'music'. By contrast with this apparent need to justify popular music in 1982, by 1998, only one comment explicitly addressed its positive musical value:

1998

-Very important to curriculum - we use it a lot...excellent vehicle for teaching many - all musical elements...it is a valid type of music which is expressive and has many examples of varied and interesting textures, timbres, structures etc.

In 1982, rather than its aesthetic value, seven teachers suggested that one reason why popular music should be included in the curriculum, was that it forms a major part of 'culture' or 'society':

1982

-Yes. It is part of our culture. It is a large and important industry...

-Yes. Important that pupils have a chance of understanding this major cultural influence.

-Yes. It is the music of today and cannot and should not be ignored...

-Yes...it is very important in everyday life and should be given a context and be seen to have a history and development...

-I often use 'pop' material...Cultural phenomenon.

-I believe pupils should be aware of the way in which society can have influence on the development of music...

-3rd Year do a 'Pop' project ... Reasons: they can study its historical development, styles, social background etc... 
In 1998, no-one said that popular music should be included for the reason that it is a major part of culture or society.

In 1982, where popular music was taught, the emphasis tended to be on history and written work such as projects, rather than on practical activities such as playing instruments, composing or improvising. The main practical activity mentioned was class singing of popular songs, often taken from musicals. Only three teachers indicated that their pupils played instruments specifically associated with popular music instruments.

1982

-Pop is covered and electric guitars etc. are available...

-Yes. I try to steer away from top 20 pop as the fashions in it change so quickly, but we have a pop group and all the instruments, drums, electric guitars, etc and I include 'pop' as the 3rd stage in my 3rd year course...

-Only minimally...My colleague teaches 'Rock music' to a group of VI formers who, on Thursday afternoons, have a choice of activities they can select. This group uses electric guitars and drumkit.

The following comments were the only three from 1982 that referred to practical work using idioms associated with popular music, although none of them specify whether the work entailed performance, composition or improvisation:

-What do you mean? We study the history of pop from 1900. Practically we work on chord structures etc. from 12 bar blues to modern musical trends.

-Yes... It also helps with rhythm work and it emphasises a lot of harmonic work that the children do.

-... 'Pop style' pieces are also used in classroom music (e.g. 'Jonah Man Jazz' and 'Daniel Jazz' which were staged with the drama department) and we also do some creative music in this vein.

As distinct from this emphasis on popular music history and written work in 1982, by 1998 only one teacher said he taught the history of popular music without also mentioning any practical accompaniment:

1998

-Yr 9 course is all to do with Development of Pop music. 1900 onwards... Four responses indicated the inclusion of current charts music in the curriculum: 
-About half of our curriculum time is spent on teaching 'popular music'. All pupils are given the opportunity to explore a range of music from a 12-bar blues to present day charts music...

-Yr 7 - none. Yr 8 - a little. Yr 9 - much more but based on less familiar styles such as blues and reggae. These are then discussed in relation to more current styles...

-A lot. Links are constantly drawn between pupils' personal listening habits and music dealt with as part of KS3/4. Parallels include harmony/structure/melody.

-Much [classroom] composition stems initially from popular music, as charts music is known by most pupils...

No-one explicitly stated that pupils did written projects or other written work on popular music, nor was there any explicit reference to listening as an end-in-itself. Singing popular music in isolation from any other activity was mentioned by only one teacher, and this did not carry any implication that it was the only practical engagement the pupils had:

-Strong emphasis on 'popular music', although incorporating a variety of styles within that genre...creates more opportunities to encourage singing, especially class singing.

All but a handful of the remaining comments from 1998 indicated that teachers incorporated at least two of the activities of composing, improvising, performing and listening to popular music. I have reproduced all the relevant comments in this area below. Some of these are also cited elsewhere in the article, but each time, within a different context. Notice incidentally too, not only the integration of these practical tasks, but that the variety of curriculum content in relation to popular music had vastly expanded, and teachers were in general, displaying far greater familiarity with both historical trends and contemporary popular music (that is, for young British teenagers in the early summer of 1998):

1998

-...Pupils prefer to compose in a popular style as they tend to understand it - they also have a clear idea as to what they hope to achieve - they are also far more prepared to sing in a popular style

-I do not teach much about pop music but use the music as examples within specific topics e.g. ostinato, instruments, etc. (Blues is a topic that is studied in $\mathrm{Yr} 8$ and we touch upon jazz as well).

-Used to relate to compositional ideas and as a comparison.

-...Yr 9 study Rock n’ Pop history, listening, composition, performing. 
-... Yr 9: one term given to the study of the development of Jazz and Popular Music including gospel singing, blues and improvisation, Dorian jazz, Rock n' Roll and 'Stand by Me'.

-All these areas come through different projects that we do, e.g. we don't teach [popular music] separately but as part of projects on ostinato/music with a story/instruments...I do favour listening examples in this style to teach the curriculum. Eg I would choose Coolio 'I'll C U when U get there' rather than Pachelbel's Canon in D or I would play both versions when teaching ostinato.

-Very little in Years $7 \& 8$, although I will use pieces to illustrate musical points. From Year 9 onwards students have every opportunity to compose in popular styles if they wish ...

-Students use keyboards from Yr 7 and are taught about chord sequences and drum patterns etc. as they go up the school. I think this is an important topic as students relate to 'popular music' and this is reflected in their compositions, performances and the music they listen to.

-I only ever use popular music to compare with other styles if there is a common idiom e.g. ostinato etc.

... I teach pupils to listen and compose music in broadest sense. How one approaches that has to remain flexible and varied. There would always be reference to aspects of 'pop' music - e.g. chord structures, style of singing, improvisation, verse/chorus, form, style etc. etc.

-Yr 7: 3 out of 10 modules use popular music as the main stimulus. Yr 8: relationships between jazz/blues and popular music. Yr 9: 50\% of the course is geared towards popular music...

-Quite a lot - pupils enjoy using for singing and performances.

-Use it for listening - structure; instruments; style. Also singing - e.g. 'Wonderwall ' - at KS3; also playing tunes/chords on keyboards with guitars etc.

-...Jazz, blues, soul, reggae, negro spirituals...A vehicle to review/teach chords, word setting...

-Large-scale assessed module in Yr 8 and many examples used anecdotally. Works excellently with Yr 8s - enthusiastic in their approach to singing contemporary tunes e.g. R. Kelly and Beatles, and this leads to extremely useful group composition work. A capella singing especially popular... 
-In Yr 9 I base the course around pop music styles starting with rock n' roll, and song writing. In Yr 8 I use Afro-European melody techniques for computers - call and response etc.

-Topics covered include:- rock'n'roll, reggae, Heavy Metal etc. Big Band (Years 8 and 9). Offers opportunity to discuss history and influence of early music; theory/part work, '3-chord trick', blues etc.

-Yr 8 - rock'n'roll. Yr 9 pop music/song writing.

-A lot. Links are constantly drawn between pupils' personal listening habits and music dealt with as part of KS3/4. Parallels include harmony/structure/melody.

-Quite a lot...it has uses for pop composing techniques and song writing. All students can attempt keyboard chord structures on pop music styles.

-Some at Year 8 a) familiar material for playing and singing b) simple construction

c) link with preceding generation. Then again at years 11-13

-Use egs. for listening. Song-writing unit Year 9.

-I try to include a wide range of musical styles...I teach 'concepts', elements through pop music and pupils enjoy performing pop music.

-Much [classroom] composition stems initially from popular music, as chart music is known by most pupils...

In 1982, only three teachers mentioned any musical elements that cut across popular music and any other style:

1982

-Not specifically but where examples of pop music can illustrate a theme we are studying then it is used...

-Yes. It...helps with rhythm work and it emphasises a lot of harmonic work that the children do.

-Only minimally. We find pop can be useful in the study of form in music in the 1st-3rd year classes...

But by 1998, as has already been mentioned in connection with the responses on classical music, large numbers of teachers indicated cross-stylistic links. Many said that they aimed to bring out 'universals' in their teaching, often referred to as 'elements', common 'concepts' or 'connections', and they often indicated that they used these across 'topics'. Here again are all the comments. Some are repeated from above, as the point there was to observe the integration of practical activities, whilst here it is to observe cross-style links: 
1998

-Lots. It is always my starting point, and I will keep referring to it. It is an important way of maintaining common language/resource...

-...excellent vehicle for teaching many - all - musical elements...it...has many examples of varied and interesting textures, timbres, structures etc.

-I do not teach much about pop music, but use the music as examples within specific topics e.g. ostinato, instruments, etc....

-I cover all the styles below in the course of every year and make every effort not only to demonstrate the special qualities of each but also to draw out connections especially with current examples in popular music...

-Used to relate to compositional ideas and as a comparison [with other styles].

-...At all stages there is an attempt to relate concepts from any style of music to other styles they are more familiar with.

-All these areas come through different projects that we do, e.g. we don't teach popular music separately but as part of projects on ostinato/music with a story/instruments...Eg I would choose Coolio "I'll C U when U get there" rather than Pachelbel's Canon in D or I would play both versions when teaching ostinato.

-I only ever use popular music to compare with other styles if there is a common idiom e.g. ostinato etc...

-I don't teach popular music - or any other sort. This sounds glib, but I teach pupils to listen and compose music in broadest sense. How one approaches that has to remain flexible and varied. There would always be reference to aspects of 'pop' music - e.g. chord structures, style of singing, improvisation, verse/chorus, form, style etc. etc. But this would apply equally to music from India, China, African Continent, Far Eastern etc. etc. 'If it fits, use it! I draw attention to, and give credence to, whatever it happens to be, but this is secondary to the musical content and method of composition.

-Some [popular music] has strong links with classical music.

-All the above [i.e. questions on folk, pop, classical, contemporary classical, jazz and world music] are covered as part of KS3 and 4 but not as discrete areas.

-...Links are constantly drawn between pupils' personal listening habits and music dealt with as part of KS3/4. Parallels include harmony/structure/melody.

-...I teach 'concepts', elements through pop music ... 
-Balance of popular-based topics often used to engage interest as the most recognised culture bridge.

-Again, we use examples of this in various schemes of work rather than focussing on it as a particular area of teaching.

\section{Jazz}

Although I did not include a specific question about jazz in the 1982 questionnaire, this style was mentioned in passing by 8 teachers. Three of the responses were in connection with popular music, one was in connection with improvisation, two with presenting an all-round history of music to pupils, and one in connection with extra-curricular activities. No teachers inserted jazz into the spaces they were given to add to the questions I asked. By contrast, in 1998, only 3 teachers stated that they taught no jazz at all, and only 6 were less than enthusiastic about it. The main reasons given by these teachers were that they lacked the necessary expertise, and/or that the pupils would find this area too difficult. Of the remaining 52 teachers, 20 were quite explicit in emphasising how important jazz was to their classroom work. Whilst four teachers mentioned that pupils enjoyed jazz, the overriding benefit was seen to be the opportunities it gives for improvisation. Indeed, there was far more emphasis on improvisation with reference to jazz than to any other style. Out of 20 such comments:

-We do teach jazz - mainly the Eddy Harvey ideas from 'Jazz in the Classroom'. Pupils pick up the melody quickly and are able to easily improvise using his methods.

-Used in improvisation skills and units on 12-bar blues and other chord patterns. Reasons as for other areas - very important style - good vehicle for improvisation which is a vital skill....

Crucial for teaching improvisation skills ...

Lots - using 'Jazz in the Classroom'. i) It creates improvising opportunity; ii) strengthens aural skills; iii) gives freedom from notation.

Jazz is not one of my best areas but I would like to introduce it more in class especially to help with improvisation...

Five teachers mentioned composition in relation to jazz. For example:

-Quite a lot...children enjoy it - can compose around it - they learn a lot about instruments from it.

-One project in Yr 9 on Blues and Jazz. One project at KS4 including composition, performance and listening...

-Yr 10/11...Composition in jazz styles. 
Although from many perspectives, jazz and blues represent quite distinct pathways in the history of popular music, 19 teachers mentioned jazz together with blues. For example:

-Used in improvisation skills and units on 12-bar blues and other chord patterns...

-One project in Yr. 9 on Blues and Jazz...

-Yr 8 - Introduce harmony (chords) with blues. Improvisation techniques using keyboards and xylophones. Yr 9 - blues in greater depth. ...

-Little - it is looked at from a historical viewpoint, and there is some work on the Blues.

-Within a 'Blues' Unit KS3 - how jazz culture came about and its origins.

Only 4 teachers made such links between jazz and popular music. As 2 examples:

-Fairly strong - usually in fairly popular forms. I'm not sure where the boundaries between jazz and popular music are!! ....

-Little, I go through the main features and types of jazz for GCSE and some work on blues and rhythm'n'blues in Yr 9 with reference to rock n' roll.

\section{World music}

As already indicated, I did not include a question on 'world music' in the 1982 questionnaire, and not surprisingly, neither that term, nor the more contemporary term 'ethnic music' appeared in any of the responses. By 1998, however, the vast majority of teachers in the sample laid quite considerable emphasis on teaching world music. Amongst the minority of 5 who were less enthusiastic, 1 put this down to the lack of available resources (a position which most of the other teachers would probably not have agreed with), and 4 others noted that they either felt unqualified or uninterested in world music:

-'Bulgarian singers' are the closest I've got to the real thing. Bartók is even more removed. I have difficulty here.

-A fair amount of time is spent on what I find is a difficult area to teach, having not been trained myself...

-Some - although not my favourite topic.

-This area gives me the least pleasure in teaching so I choose to do the minimum.

The remainder of the teachers were generally, very positive. One main reason was that they felt world music raised pupils' awareness of other cultures: 
-We include at least 1 x 4-6 week unit each year...Reasons:...Raise awareness, understanding and appreciation of cultures outside our experience.

-Very strong, to give broad range of experience, access musical ideas and skills from different directions and...strengthen [pupils']...respect for each others' cultures.

-In Years 7 - 9 I make sure all students receive some experience in Indian, Gamelan, Chinese and some African music because it is important for them to experience music from other parts of the world as well as to realise that these musics can provide valuable musical experiences in their own right.

-Every year from 7-11 covers a project on world music. Musicians are invited to perform to students e.g. Gamelan group, Indian, African drumming, Chinese, steel pans, etc. This is of great importance for students to put their own experiences into context with music from around the world.

-All years learn a scheme on the music of China, Jamaica and India. Not only do they learn about the music, they are introduced to different cultures. Indian music is taught cross-curricular with the RE and Drama department.

-World music is essential in teaching the value and respect for music and musical styles of other cultures...

-World music is important and is an ingrained topic throughout all schemes of work. It enables children to gain an understanding, through studying other music, of other cultures in the world. It also...introduces them to a whole new style of music they would otherwise never hear.

-Some - to maintain an awareness of how music is used in other cultures.

-...Our school is very multi-cultural in terms of its intake also so [world music] is particularly relevant.

A number of teachers also included world music in order to reflect the diverse ethnic backgrounds of their own pupils.

-Very strong to give broad range of experience, access musical ideas and skills from different directions and to utilise students' cultural backgrounds and so strengthen their group identities and respect for each others' cultures.

-Some, this is a multi-cultural school.

-Vital - we have an International Evening every year - pupils from a rich variety of ethnic backgrounds. 
-Yr 8: Indian Classical Music. Yr 9: Irish, African, South American. Excellent opportunity for representing/enhancing what is a very multi-cultural school...

-A great deal...Pupils are encouraged to bring music from their country of origin and to share it with their class.

-Units include: African, Indonesian, Indian, Blues, Folk, Caribbean - reflecting the cultures of pupils in this school.

-A small amount. Pupils are invited to bring in, introduce and play their CDS and tapes which is rewarded and listened to.

-This sharing is an important part of the curriculum because it represents the heart of the school. We all learn from each other.

-More [than all other areas except popular music]: we are a 97\% Bengali intake school.

Two stated that pupils are open to world music.

-A lot - more than any of the above. They (the students) cannot categorise world music like they categorise/criticise classical music. No snap judgements can be made.

-World music is essential in teaching the value and respect for music and musical styles of other cultures. Often pupils laugh when they first hear 'World' sounds but when they have made an attempt at composing or performing they develop a respect.

Only one mentioned the problems associated with tokenism:

-Very very little...I do not think we can imitate the sounds of authentic instruments though we can understand concepts of how pieces are built up. Lack of curriculum time one period (1 hour) a week Yr 7-9. I could not do justice to Indian music, e.g. in a 6week module. I would find it insulting if someone attempted to teach Western music in a similar amount of time!

\section{Summary and further questions}

Whilst the term 'folk music' inspired little enthusiasm from teachers in both 1982 and 1998, the meaning of the term had widened to include global perspectives by the end of the century. Around half the teachers were positive towards 'avant-garde' and 'creative music' in 1982 and towards '20th century classical music' in 1998; but the levels of negativity and concern about practical work expressed in the earlier survey had considerably diminished by 1998. Furthermore, practical, creative work had no more associations with atonal music by that time than with any other musical area. Again, as with folk music, new in 1998 was a tendency to forge 
cross-stylistic connections, mainly between twentieth-century and pre-twentieth century classical styles, but with one mention of fusion and one of Gamelan.

Whilst teachers' commitment to and respect for classical music do not appear to have lessened between the two questionnaires, the implications of many 1982 teachers, that classical music deserved to take up the most curriculum time on the basis of its superiority and its unquestionable status as cultural heritage, appeared to have considerably waned. Instead, teachers in 1998 were more likely to perceive the classical area as a music among musics, one of enormous value but not necessarily the prime contender for space on the curriculum, nor a music to be grasped in cultural or historical isolation. Once again, in many cases, rather than emphasising its unique properties, teachers were instead, concerned to demonstrate those properties which it holds in common with other musics.

Although three-quarters of the 1982 teachers did include popular music in their curricula, there was nonetheless considerable doubt and negativity surrounding it. Many teachers considered it either unnecessary, impossible or intrusive to teach, and many used it predominantly with lowability pupils or ' 3 rd years', after the main part of the general music course was complete. Whilst there was an emphasis on the relevance of the music for pupils, this was coupled with the notion that it should be taught in order to make pupils more discerning and able to distance themselves from the mass media. Whilst teachers readily and unquestioningly assumed the value of classical music, when it came to popular music they were more defensive in asserting its musical value. At the same time, many regarded its links to 'culture' and 'society' as important, rather than emphasising its musical qualities. The main approach was through music history lessons, with practical activities largely focussed on class singing. By 1998 teachers' doubts and negativity had given way to an overwhelmingly positive reception of popular music and its presentation as an equal alongside other musics. One major new factor was to encourage a strong practical engagement with popular music, involving composition, improvisation and classroom performance as integrated activities. Another was the use of popular music to teach 'universals' that cut across musical styles, embracing folk to art music from a variety of historical and geographical origins.

By 1998 the position of jazz in the curriculum had shifted quite radically, from a passing mention by 8 out of the 61 teachers in 1982, to 58 of the 61 teachers stating that they used it in 1998 . Perhaps the greatest area of change was in the position of world music, which entered the 
curriculum with a bang, from having no discernible presence in the 1982 survey, to a position of enormous importance apparently on a par with classical music by 1998 .

It is tempting to seek explanations for such changes mainly in the legal stipulations of the National Curriculum which, as mentioned, made it mandatory for teachers to include a variety of styles and activities from 1992 onwards. Taken from this point of view, it would seem that teachers did not choose, but were forced to embrace a far wider variety of music and activities than had hitherto been the case. However on inspection, any suggestion that teachers changed their practices merely in response to governmental stipulations seems untenable. For one thing, teachers were themselves very largely supportive of the National Curriculum, which it can be argued, was based on existing good practice. For another thing, if it was the case that teachers were slavishly following legislation, then there is no explanation as to why for example, 'world music' should have received so much greater attention than folk music by 1998. Therefore it seems reasonable to suppose that any changes in teachers' practices were motivated to a significant extent by factors other than legal requirements.

These factors involve broad social changes outside education: indeed it was such factors to which the National Curriculum was itself responding. They include developments in technology, globalisation and localisation practices, demography, and gender, social class and race relations. In the sphere of music, electronic instruments and computers had developed in ways that profoundly affected performance and composition practices. Ever more efficient and cheap equipment for sound-recording and reproduction, along with the expansion of the music industry, had made a huge variety of global musical styles available to large numbers of listeners from almost any walk of life. The relationships of people from differing social groups to music underwent rapid changes: certain styles of music were no longer exclusively associated with certain social classes; women in some parts of the world became less restricted in their musical roles than previously; and particular musics no longer 'belonged' primarily to particular ethnic groups. Educational policies in general responded to the presence of ethnic minorities in 'host' cultures, in ways that were less assimilationist and more multi-cultural.

A close examination of such changes and their implications for music education would be a major task, far beyond the scope of the present article. My hypothesis is that we are witnessing a sea-change in music education, inspired by new practices, values and identities in the globalised and localised musical world we all inhabit. But although such changes are apparent, at the same 
time, a number of classroom approaches today still retain very traditional aspects. Contemporary teaching strategies, which historically developed in conjunction with classical music pedagogy, have not necessarily shifted as much as the many changes in curriculum content would suggest (Green 2001). Alongside formal music education, informal methods of acquiring musical skills and knowledge have always flourished, leading to the production of most of the world's popular, traditional, classical and jazz musics throughout history. Whilst schooling has recently incorporated a wider variety of musics into curriculum content, I would suggest that one of the tasks now facing music educators, not only in schools but higher education too, is to make a serious assessment of the very different learning practices by which these 'other' musics have been passed down, and a consideration of what light such practices might shed upon our own.

\section{Glossary}

CSE: Certificate of Secondary Education; a national examination mainly for pupils aged 14-16, of lower status than the O-level which ran concurrently with it until they were replaced by the GCSE in 1986.

GCSE: General Certification of Secondary Education; a national examination mainly for pupils aged 14-16, covering all ability levels and in 1986, replacing the earlier combination of CSE and O-level.

KS3: Key Stage 3; pupils aged 11-14; i.e. Years 7-9 of the National Curriculum.

KS4: Key Stage 4; pupils aged 14-16; i.e. Years 10 and 11 of the National Curriculum, mostly in the case of the current data, taking Music GCSE.

NC: National Curriculum; established in 1992 separately for England and for Wales.

O-level: Ordinary Level; a national examination mainly for pupils aged 14-16, of higher status than the CSE which ran concurrently with it until they were replaced by the GCSE in 1986.

Years 1, 2, 3, 4, 5: pupils aged 11 to 16, up to 1992.

Years 7, 8, 9, 10, 11: pupils aged 11 to 16 after 1992. 


\section{Bibliography}

DENNIS, BRIAN (1970), Experimental Music in Schools, Oxford: Oxford University Press.

DEPARTMENT FOR EDUCATION (DFE) (1995) Music in the National Curriculum (England), DFE.

GREEN, LUCY (1988) Music On Deaf Ears: Musical Meaning, Ideology and Education, Manchester and New York: Manchester University Press.

--------(2001) How Popular Musicians Learn: A Way Ahead For Music Education, London and New York: Ashgate Press.

KUSHNER, SAVILLE (1991) The Children's Music Book: Performing Musicians in School, London: Calouste Gulbenkian Foundation.

PAYNTER, JOHN AND ASTON, PETER (1970) Sound and Silence: Classroom Projects in Creative Music, Cambridge and New York: Cambridge University Press.

SCHAFER, MURRAY (1967) Ear Cleaning: Notes for an Experimental Music Course, New York: Associated Music Publishers Incorporated

SELF, GEORGE (1967), New Sounds in Class, London: Universal Edition.

SWANWICK, KEITH (1968) Popular Music and the Teacher, Oxford: Pergamon Press.

VULLIAMY, GRAHAM (1977), "Music as a case study in the "new sociology of education"' in John Shepherd, Paul Virden, Trevor Wishart and Graham Vulliamy (1977) Whose Music: A Sociology of Musical Language, London: Latimer New Dimensions.

[10,979 words including Abstract, Glossary, Bibliography and Endnote] 


\begin{abstract}
Note
${ }^{1}$ One or two points of explanation are in order for any readers unfamiliar with the English education system. However, such readers should find that they can readily appreciate what the teachers are saying, without necessarily internalising these terminological details. I have additionally provided a Glossary for anyone left in doubt. In 1982, pupils aged 11 to 14 were organised in year-groups labelled 1,2 and 3; by 1998 the same age-groups were labelled as year-groups 7, 8 and 9 respectively. In 1982, pupils from age 14 to 16 could opt for either music O-Level, the exam for 'higher ability' pupils, or music CSE, the exam for 'lower ability' pupils. After 1985, pupils opted for a single exam designed for all ability groups, called the GCSE. In 1992 the government introduced a National Curriculum (NC), which for the first time in British history, made stipulations as to curriculum content and outcomes. After 1992, school years 7, 8 and 9 are sometimes classed together as Key Stage 3 of the National Curriculum (or KS3), and years 10 and 11 as Key Stage 4 (KS4).
\end{abstract}

